\title{
Glamor face of narcissism: an analytical approach
}

\begin{abstract}
The paper studies the structural organization of the narcissistic personality of the subject. Identify the basic elements of the disposition of the ego "narcissus", revealed the strata of the narcissistic personality, studied systemic causes of the emotions of the dyad "grandiosity-nothingness." The text ratio is updated in the structure of the individual true and false aspects Self, identified these two parts forming ego the stages with narcissistic personality. The article is illustrated with case studies of group therapeutic work.
\end{abstract}

Keywords: narcissism, narcissistic structure of the narcissistic personality type, work with narcissism in psychotherapy
Volume 9 Issue 6 - 2018

\author{
Valery Romanovich Dorozhkin \\ Department of Psychology and Psychotherapy, Institute training \\ of civil service employment, Ukraine
}

\begin{abstract}
Correspondence: Valery Romanovich Dorozhkin, Assistant professor of Depth Psychology and Psychotherapy, Professor of Psychology and Social work of the Institute training of civil service employment in Ukraine, Kiev, Ukraine, Email valador2007@gmail.com
\end{abstract}

Received:September 12, 2018 | Published: November 26, 2018

\section{Perspective}

The study of narcissism as a phenomenon and as a type of personal organization in a large number of works in the first place, the representatives of the psychoanalytic school. Freud, G.Ammon, M.Balint, D.Vinnikot, O.Kenberg, M. Klein, H.Kohut, Zh.Lakan et al. Describe not only the notion of theory, but also on the basis of this summary is the practice of a narcissistic type of personality organization. Freud first began to use the "narcissism" as a term in 1910, and the details paid attention to him in his work "On narcissism". ${ }^{1}$ Founder psychoanalysis considered two kinds narcissism - primary (autoerotism) and secondary. According to Freud, the primary narcissism appears still in its infancy, to highlight instances I of Eid, when a child is experiencing an undifferentiated pleasure from their own body, and fixes to their last libido. As they get older, the child redirects libido on objects, causing him or gives him pleasure (primarily on the mother or the figure, it replaces). The stage of primary narcissism, Freud considered a necessary stage of libido development, and considered this step as a precursor object relations. By the way, I note that, later, the concept of primary narcissism was criticized by M. Klein, who believed that object relations exist already in the first months of life. ${ }^{2}$ Secondary narcissism or narcissism I arises, as Freud thought, when the libido is extracted from the relationship to the subject and reiterates and fixed at J. According to Freud, this process has already pathological. "Secondary narcissism is expressed in a pathological egocentricity, lack of ability to establish productive object relationships, the inability to accept other people the right to independence aspirations". ${ }^{1}$ Balint $\mathrm{M}^{3}$ considered pathological narcissistic component, as a result of violation of the relationship in the early stages of development, which he defined as the dyadic or preverbal. Balint's view was that a secondary narcissism is the nature of the deficit is a consequence of the underlying defect associated with the lack of communication with the mother in the first months of life.

On the deficit nature of malignant narcissism and insists G.Ammon - author of "dynamic psychiatry" concept. ${ }^{4}$ As part of its approach Ammon considering three types of narcissism - a constructive, destructive and deficit. The last two are associated with the failure of the child when leaving early symbiosis with the mother figure and the formation of so-called "self-delimitation deficit" when significant others, and here and here, at the same time. In this case, after Freud Ammon determines initial narcissistic, firstly, as a primary structural requirement of the person, and, secondly, as a result of internalization specific experience with other people. According to him, pathological narcissism takes, t. E. destructive or deformed nature of the deficit only by a corresponding negative experiences in the family group. Ammon argues that the development of a narcissistic personality structure can not take place, since this is prevented by a deep existential and vital archaic fears. It is these fears do for people narcissistically deficiental impossible to internalize so coveted, and they need support from the outside narcissistic. Differences from destructive narcissism deficit Ammon saw that in the last psychogenetic plan is the development of the first, the exacerbation of it as a result of further pathological destructive-narcissistic dynamics. When destructive narcissism upset or distorted by the relationship of man to himself, to others and to the world around them, people can not adequately assess themselves, overestimate or underestimate their abilities, they oscillate between fantasies of grandeur and self-deprecation. When narcissism deficit people do not develop a sustainable attitude. According to Ammon deficit narcissistic person is unable to take seriously their thinking, feelings and actions and defend them. At the same time, Ammon detailed researches and constructive narcissism, which, in his view, encompasses the ability to love yourself and treat your unconscious. At the same time it is not about narcissism, but of a form of selflove, which is accompanied by a joyous, passionate statement of their physicality, their interests, ideas and spirituality. "Structurally, the narcissistic person feels as an individual with the right to own thinking, their own perception and their own way of life". ${ }^{4}$

The particular view of narcissistic presented in papers Kernberga O. ${ }^{5}$ On the one hand, the scientific adheres trunk line psychoanalytic views on narcissistic consisting in the fact that the roots of this phenomenon are the result of a child and the parent or malevolent indifference education. On the other hand, Kernberg focuses on the description of the narcissistic personality disorder (ADRs) in the adult personality. According to the author, especially self-awareness and self-representations in people with narcissistic diagnosis are as a sensation of emptiness, falsity, shame, envy, or in polar experiences 
- self-sufficiency, vanity, superiority. Kernberg describes these as opposing polarity condition in the perception of self, the vile, the grandiose. The author argues, that the data polarity is the only possible organization of the internal experience of the individuals suffering from ADRs. A feeling that they are "good enough" is not included in the number of internal constructs such individuals. Kernberg ADRs refers to the boundary condition in which there is identity diffusion, primitive defenses dominated, first of all - the idealization and devaluation. The author points out that these two types of defensive mechanisms is the feedback: the idealization of self importance and the role of other people is impaired, and vice versa. Kernberg's focus on the pathological aspects of narcissism in the adult personality allowed him to discover the new features of ADRs, among which he described the enormity and grandeur, psychological hunger and "oral rage". ${ }^{5}$ NLR suffering. A feeling that they are "good enough" is not included in the number of internal constructs such individuals. Kernberg ADRs refers to the boundary condition in which there is identity diffusion, primitive defenses dominated, first of all - the idealization and devaluation. The author points out that these two types of defensive mechanisms is the feedback: the idealization of self importance and the role of other people is impaired, and vice versa. Kernberg's focus on the pathological aspects of narcissism in the adult personality allowed him to discover the new features of ADRs, among which he described the enormity and grandeur, psychological hunger and "oral rage". ${ }^{5}$ NLR suffering. A feeling that they are "good enough" is not included in the number of internal constructs such individuals. Kernberg ADRs refers to the boundary condition in which there is identity diffusion, primitive defenses dominated, first of all the idealization and devaluation. The author points out that these two types of defensive mechanisms is the feedback: the idealization of self importance and the role of other people is impaired, and vice versa. Kernberg's focus on the pathological aspects of narcissism in the adult personality allowed him to discover the new features of ADRs, among which he described the enormity and grandeur, psychological hunger and "oral rage". ${ }^{5}$ Kernberg ADRs refers to the boundary condition in which there is identity diffusion, primitive defenses dominated, first of all - the idealization and devaluation. The author points out that these two types of defensive mechanisms is the feedback: the idealization of self importance and the role of other people is impaired, and vice versa. Kernberg's focus on the pathological aspects of narcissism in the adult personality allowed him to discover the new features of ADRs, among which he described the enormity and grandeur, psychological hunger and "oral rage". ${ }^{5}$ Kernberg ADRs refers to the boundary condition in which there is identity diffusion, primitive defenses dominated, first of all - the idealization and devaluation. The author points out that these two types of defensive mechanisms is the feedback: the idealization of self importance and the role of other people is impaired, and vice versa. Kernberg's focus on the pathological aspects of narcissism in the adult personality allowed him to discover the new features of ADRs, among which he described the enormity and grandeur, psychological hunger and "oral rage". 5 and vice versa. Kernberg's focus on the pathological aspects of narcissism in the adult personality allowed him to discover the new features of ADRs, among which he described the enormity and grandeur, psychological hunger and "oral rage". ${ }^{5}$ and vice versa. Kernberg's focus on the pathological aspects of narcissism in the adult personality allowed him to discover the new features of ADRs, among which he described the enormity and grandeur, psychological hunger and "oral rage". 5
Kohut $\mathrm{H},{ }^{6}$ following Freud developed the idea that the narcissistic libido and object libido have independent power sources, separate lines of development and transformation, and reflect the different kinds of experiences. But unlike the founder of psychoanalysis, Kohut suggests that narcissistic and object libido always cathected objects: Only in the case of object libido they are real objects The separate from the subject; and in the case of narcissistic libido - the images I object. ${ }^{7}$ Narcissism, according to Kohut, is a "psychological glue" that holds the connectivity of the elements in I and connects the current identity representations of themselves into a single Self. Formation of a healthy narcissism serves an integral part of normal mental development of man, is the necessary basis for the formation of self and its positive self. Healthy mental development Kohut describes as a gradual falling away of the most serious aspects of unrealistic self-image object with the internalisation of external relations with the self-object in a stable mental structure. This process Kohut called "transmuted (transforming) internalization". 7 The process of "run" from the very early age naturally and inevitably increasing disappointment in himself and in the idealized self-object. Such disappointments are due to the impossibility of merging with the selfobject, that to some extent frustrates the basic desire of the child. When the frustration, which leads to frustration, is the optimum stage of development - this attracts growing maturity of the ego; If frustration is not optimal, it leads to the formation of a grand I archaizing Ego idealizing self-object to the overvalued status. Described pathological processes Kohut, unlike Kernberg, said reversible, and itself formed by malignant narcissistic he considers not as a pathology, but as a delay in the development of the individual and felt that this person is possible to return to step interrupted development and the pre-form healthy shape narcissistic . Along with the described performances, Kohut also introduces the concept of "narcissistic expansion." The latter occurs in a situation where children are an extension of the ego and the parents receive from their love, as payment for the expected role behavior from them. In this case, the true Self of the child is rejected, and in its place set false self, made up of a set of parental expectations, regulations and directives. Heartache. Finally, one more look at narcissism, presented in the works Vinnikota $\mathrm{D}^{8}$ and Lakana. ${ }^{9}$ Both authors attribute the formation of a narcissistic fascination with the phenomenon of mirroring. Winnicott believed that the child otzerkalivayut eyes and his mother's face, which reflect all its wonderful charm/or mirrors his cold and empty. Lacan same as the key points considered mirroring step Mirrors on which the child falls and samootozhdestvlyaetsya with perfect gestalt manner himself in the mirror. "Passionate love object to its image - narcissism generated by the mirror stage". ${ }^{9}$ As a result, the child takes the foraminous shell for itself, in the mirror. Moreover, it replaces itself on the other - of who actually is not. "I samootozhdestvyalyaetsya with the image of the other. Phenomenology of the concept of "narcissism" is revealed not only in theoretical structures of various authors. It helps to clarify the practice of psychotherapy. The latter allows you not only to understand narcissism as an experience, but also to study it in intersubjective interaction space. Below I cite the case of group therapy, in which the narcissistic type of relationship is disclosed clearly enough. For the opportunity to explore and present this case, I am grateful to Victor - one member of the treatment groups. Group held in psychodynamic format and had a constant composition and abundance. As for Victor - this is a man forty years old, tall, adynamic build, with an introverted character warehouse and constantly pensive expression on his face. 
Victor spoke about love and began by saying that he could not find a decent darling. He was married, divorced from his first marriage left a daughter. From the words of Victor, after the divorce, he had other women, but they are somehow not "cling" him, he did not find them that appeal to themselves, for the sake of which would be ready to start a new relationship. Recently, Viktor "lost all hope," and his need to find a woman has become a satisfying sexual needs.

Honestly, I stopped believing that I could meet that unique, which is designed for me and I can not find. Or maybe I do, somewhere lost it.

\section{Lost?}

Lost ... I was love, the perfect girl for me, and I did not dare run away, missed the sight of her, and then it was too late to change anything. Life is twisted, I started dating his future wife, she became pregnant, gave birth to a daughter, we got married, and everything went on as usual. Many years later I met this girl again. I even sat with her at the same table at the festival from our factory. Then I wanted to talk to her, but ... lost heart. And then she began to call his wife, I had to go, and I did not tell her about his feelings. Since then, I have not seen her.

Please tell us a little more about how you met her. Who is she? Where you met her? How we met?

Yes, I never met her, in general, ...

is not met?

Yes, is not met. At the moment of acquaintance with her I had another girl. Not to say that I particularly like it, but, in principle, it was pretty good and I spent a lot of time with her. And we did not even have sex. Rather, it was the friendship with love elements. Although ... that our meeting meant for her, I can not judge. I was never interested. So, after a couple of months of relationship, my girlfriend invited me to his birthday party. I came in and saw her ... fifteen years younger sister. And I, by the way, at that time was twenty-two years! Can you imagine?

\section{What is it present?}

The difference in age. So, I'm sitting at the table, and he can not take his eyes off her. She is slim, even thin air, some whole unearthly, to food is not touching, drinking only juice, charming smiles somehow his thoughts and modestly, only occasionally sneak looks at the others and me ... It was then that I love and proshibla ... I fell in love with her at first sight. I started overflowing adoration for her, and not to betray myself, I began to look at his plate. It is ridiculous to say, but I was afraid to raise his eyes. And if you remember, I came to the birthday guy her sister! And that's what you ordered me to do? I sat there for a couple of hours, got up and left. That evening I decided to leave her sister not to see with my love. I could not with both of them to do so.

\section{How exactly do?}

Oh. I began to meet with a girl, and two months later gone over to her sister. This is not for me. I can not do, you know?

\section{And what did you do?}

to break off a relationship with them and the more they have not seen. Almost immediately I began to walk with one of his friend, then another, then another one. A little later, he met his future wife, married, divorced. I already told all this.
Wait, - began one of the members of the group - do you want to say that I saw a girl, about whom you tell, only twice in my life?

Well yes...

Now comparing all women with her, and they were not up to it?

Yes, but I also speak about it. Although ... It is not that other women before her did not reach, rather, I did not have them such a strong feeling. And I want it a sense, the same thrust, as it experienced it.

The story of Victor provoked heated discussions in the group. Participants began to share their attitude to hear from the man's history. There were opinions that Victor "ran away from the relationship and continues to run away from the senses." Some of the participants experienced the anger and indignation at the narrated story. One representative of this group even said:

You betrayed my love, and now punish myself. So who needs your self-punishment? The girl or do you? Know that women need feelings! And what do you do now the self-limitations and make yourself miserable - it is you do for yourself, not for her. This is your personal business.

Several people began to discuss the nature of the "idealization of the partner and the relationship with him." They concluded that the idealization happen more often than less real experience of human contact, and amplified when the relationship itself more and more lost in the depths of personal history. The discussion involved the participants; They forget about the Victor, and his feelings. Suddenly, one of the men took a provocative stance:

Victor, here explain to me how can match any real woman who eats, drinks, blowing his nose, goes to the toilet, which, moreover, can be not agree with you on some vital issues and decisions, that's how it It can be compared with a modest, thin, air, woven of some clouds and ether heavenly girl fifteen years, which is nothing but the juice and does not consume at all?

Victor stood dumbfounded. Meanwhile, a man quite emotionally continued.

Any woman would lose such a comparison. After all, the comparison with the ideal, the perfect girl that you captured on the basis of a imprinting. You are, figuratively speaking, took a picture of it, and you have encountered an internal feeling that she is this: all the time sitting at a table, with her modest eyes, does not talk, does not consume any food, has some of its principled position and ... in need of your protection, since besides more and "timid". Over time, the pedestal on which you lifted it in his soul, becoming higher and higher, and now it occupies the place that belongs to other people, such as God or someone no less ambitious than he is. And now tell me, how is it that in the place of God in you is the juvenile girl? What are the commandments, but worship it, you must comply with?

The band members laughed. Victor, however, continued to remain silent, but the tension was replaced by his curiosity.

But the most important thing is not the point. After all, who could love a girl of fifteen? Only a boy of fifteen. In my opinion, it gives hope for you that you are - it's just a shell of the man that hides a fragile, romantic, fine mental organization youth. And while alive fantasy about a girl alive until this fantazmatichny boy. And how do you use her image? You made him a sealed container, in the words of our therapist, in which skladiruesh their idealized representations. 
And everything else that does not meet the requirements of an elevated and pure, gets real the women, of whom you also make containers for trash only. The two objects - the ethereal girl and a real woman - split you into two entities. In this case, one of them well hidden in the image, imagination and can not be tested any reality, as never in the space of reality not materialize. Here is I had an opinion about your story. When we, shaking off emotional tirade, looked at Victor, we found that it looks quite helpless, and even crushed. The feeling that ripped clothes, and sometimes even the skin with him, and now, left naked in the middle of a circle of people whose presence he is also, incidentally, saw for the first time. Victor felt a burning shame and a desire to hide behind to give us something, but remained silent and inactive. It seemed that he bowed his head waiting for the final verdict - live it, or group will make a death sentence. By his own experience, the band members saw him as he felt himself at that moment: a helpless, pitiful living in illusions loser who could not keep the family together, and fueling ephemeral feeling only in order not to see himself and his image life. For Victor it was stress, shock therapy. And the shock he experienced not by spoken words. They did not embarrass him. Above all, he was crushed by the fact that with its fantastic design, which he fostered and which has been repeatedly imposed on others to give them sympathy, in an instant, without due respect for the upholstery fabric ripped. And under this cloth is not only found chrome, brilliant feeling, but even he was not rusty skeleton, and there was only one empty. It is, in his own words of Victor, granted him bankrupt. At the same time the event itself took place in public. Now, who he knew. Panic - that's the feeling that flooded Victor, instantly burned out it was replaced by apathy and depression. Now do with me what you want - it is broadcast to the group. And the shock he experienced not by spoken words. They did not embarrass him. Above all, he was crushed by the fact that with its fantastic design, which he fostered and which has been repeatedly imposed on others to give them sympathy, in an instant, without due respect for the upholstery fabric ripped. And under this cloth is not only found chrome, brilliant feeling, but even he was not rusty skeleton, and there was only one empty. It is, in his own words of Victor, granted him bankrupt. At the same time the event itself took place in public. Now, who he knew. Panic - that's the feeling that flooded Victor, instantly burned out it was replaced by apathy and depression. Now do with me what you want - it is broadcast to the group. And the shock he experienced not by spoken words. They did not embarrass him. Above all, he was crushed by the fact that with its fantastic design, which he fostered and which has been repeatedly imposed on others to give them sympathy, in an instant, without due respect for the upholstery fabric ripped. And under this cloth is not only found chrome, brilliant feeling, but even he was not rusty skeleton, and there was only one empty. It is, in his own words of Victor, granted him bankrupt. At the same time the event itself took place in public. Now, who he knew. Panic - that's the feeling that flooded Victor, instantly burned out it was replaced by apathy and depression. Now do with me what you want - it is broadcast to the group. he reared and which has been repeatedly imposed on others to give them sympathy, in an instant, without due respect for the upholstery fabric ripped. And under this cloth is not only found chrome, brilliant feeling, but even he was not rusty skeleton, and there was only one empty. It is, in his own words of Victor, granted him bankrupt. At the same time the event itself took place in public. Now, who he knew. Panic - that's the feeling that flooded Victor, instantly burned out it was replaced by apathy and depression. Now do with me what you want - it is broadcast to the group. he reared and which has been repeatedly imposed on others to give them sympathy, in an instant, without due respect for the upholstery fabric ripped. And under this cloth is not only found chrome, brilliant feeling, but even he was not rusty skeleton, and there was only one empty. It is, in his own words of Victor, granted him bankrupt. At the same time the event itself took place in public. Now, who he knew. Panic - that's the feeling that flooded Victor, instantly burned out it was replaced by apathy and depression. Now do with me what you want - it is broadcast to the group. but even he was not rusty skeleton, and there was only one empty. It is, in his own words of Victor, granted him bankrupt. At the same time the event itself took place in public. Now, who he knew. Panic - that's the feeling that flooded Victor, instantly burned out it was replaced by apathy and depression. Now do with me what you want - it is broadcast to the group. but even he was not rusty skeleton, and there was only one empty. It is, in his own words of Victor, granted him bankrupt. At the same time the event itself took place in public. Now, who he knew. Panic that's the feeling that flooded Victor, instantly burned out it was replaced by apathy and depression. Now do with me what you want it is broadcast to the group.

Naturally, with Victor nobody did anything. A man supported and said they take it as a unique personality to a much greater extent than in the beginning of the story. Moreover, the participants called it compassion and love .... That's what struck him most. Indeed, he believed that deserves contempt and hatred and these feelings projected in the group, waiting to get their feedback. He did not understand what was happening, was disoriented, vulnerable, but also open to the world, absorbing new, like a sponge. By the way, all the dynamics of feelings that I give here, we discovered much later, at the next meetings. At the same time, Victor was silent and helpless, but, nevertheless, eagerly listened to everything that is discussed in the group.

If we use the international classifier DSM-IV personality disorders, ${ }^{5}$ that on several grounds we find Victor narcissistic personality type. $\mathrm{He}$ is present belief in the uniqueness of its own, which can evaluate only the elect, "special" people (psychologists); it exploits others in interpersonal relations, without thinking about their feelings; empathy skills he does not have, other people's emotions, he can only "know" that determines their intellectually; occasionally it occurs subjectively unbearable feelings of shame for himself. I do not set myself the goal to find out "diagnosis", and want to agree that the identity of Victor can be seen as an illustration of this type of mental organization, in which narcissism has a considerable weight. If we accept this agreement together, then,

1. Structure of representations about what other people feel, the "Narcissus" is very specific. This is due to the fact that the narcissistic person does not "feel" of people, and finish building their emotions intelligently. That is, in the structure of their way of pronounced cognitive component. On the example of Victor I will say that he has repeatedly received such an assessment in the feedback from the participants, but it did not cause him empathy response. Rather, he felt resentment from cognitive misses when they happened. The same may be said about his own feelings "daffodils." "Intellectualization" narcissistic experience allows subjects to experience them indirectly, pre-wrapped in a cloth of some sort of "know" stories. In these stories a sense of "Narcissus" acquire new, fanciful meanings, turns them into artificial formation - a kind of intellectual and emotional design, painkillers their inner world. With these designs narcissistic personality touch their true 
emotions and feelings. By the way, Victor issued his feelings in the packaging, "the story of unrequited love," and thus authorized to yourself the opportunity to experience the real emotions that this story is connected.

2. Intellectualization narcissistic personality senses is achieved by another of its important features - the ability to close your inner world to itself. ${ }^{10}$ This special ability allows the "Narcissus" experience feelings in their "no-object" format. Here I mean the fact that the person tied to the narcissistic type of real objects is much less than the internal. But not even that is "no-object "experiences format. Own feelings for "daffodils" priority projects, they overshadow them all, inherent in the object of emotions. This leads to the fact that other people's images are flattened in narcissistic personalities, not multi-dimensional and two-dimensional, single-valued, poorly differentiated from one another. Between the images of the "Narcissus" of the object builds the cognitive network of connections, which retains its identity in the "know" its borders and closes on itself. Natural voids in the network are filled narcissistic subjects using cognitive reformatting real relationships and to create new, artificial under an hour, and even fanciful meanings. All together it creates a false Self -. Protection circuit identity "daffodils" formed by them, mainly cognition, "know" experiences safe stories and so narcissistic personality easily impose this circuit ready to discuss it, to work with him and his reformat but are not allowed inside, for him. It is this feature of them creates a feeling of tightness of their personalities and the inability to break through the protective circuit for the "facade" of relations. In this case, the real Self is hidden not only from others but also from themselves "daffodils." In the structure narcissistic personality Self alienated real and false rejected from Self. In its disposition, they look like the "core" and "shell" of the individual, which practically do not touch each other. The "core" is overloaded with emotions, and the "shell" - cognition. When the attention of the "Narcissus" is concentrated in the true Self, it was "flooded" the senses; and when it enters the "envelope" - that gets to secure the cognitive field. With the "core" and "shell" associated basic sense of "daffodils." Plunging into true Self narcissistic person feels anxiety, shame and insignificance; placed in a false Self, she falls into a state of intellectualization or experiencing a feeling of grandeur. This is achieved if the false answers Self-ideal ego.

3. The consequence of the above features of narcissistic personalities is that their relationships are formal, superficial and "distant" character in the treatment group. The therapy transference reactions and feelings to the other participants in the "Narcissus" is practically not formed, the transfer to the therapist does not arise. If the relationship and added, that very specific cognitive properties - in the form of interest to intellectual psychological game. In other words, a transference reaction "narcissus" can only speak as a "cognitive" transference. At the same time, the presence of an object narcissistic personalities (and sometimes, as in the situation with Victor, very specific - teachers, psychologists), in which they displace the function of critical evaluation and frustrations themselves. The images of these objects fall into the already formed specific parent-child relationship niche, that is a substitute for the primary self-object, glued on them. In this case, the substitution itself is conditional, since the main function aggressive or cold, indifferent attitude to itself - is stored. As in the case of interaction with primary self-object, in a situation of relations with the new objects of the narcissistic personality is not dopoluchaet positive mirroring itself. "Daffodils" These images I object in the psychic world I call quasi-negative. These images are overly idealized, they cathected significant amount of libido, which makes them valuable for "daffodils." The extent of this value corresponds to the distance between the false contour Self cognitive and emotional core true H. In the inner world "daffodils" true Self can never come close to the ego-ideal, that develops a sense of insignificance. At the same time, a false Self can enter the position of the images I object or ego-ideal when answering their perceptions about their expectations. This process results in a narcissistic person to experience a sense of grandeur. Needless false Self is not retained on the ego-ideal position for a long time. The latter is due to the fact that a sense of grandeur inflates a false Self, assigning images of idealized objects farther away. To illustrate this process will use the analogy of a balloon. If applied on the surface of the two points and begin to inflate the balloon, then the distance between them will increase. Described psychic dynamics creates the "Narcissus" disappointed in himself and the loss of faith in the attainability of the idealized self-object. Even more traumatic for narcissistic personalities experience the true Self. They tend not to be in contact with that part of the ego, are ashamed of it, hiding and otherwise drape including anesthetic feeling of emptiness, but from time to time fail in it, reliving insignificance.

The "Narcissus" can be self-object relations with which are built on the principle of projective identification. In the absence of real knowledge about the object, if the lack of direct relationship, "daffodil" projects his love to the object, and then allows himself to experience it. The latter, as a rule, can not be tested by the very reality of the lack of relations. Images of the objects for which projected positive feelings can be called conditionally positive in psychic reality "narcissus". To conditionally positive image cathected significant amount of libidinal energy that makes them inaccessible to subjectively true Self. Narcissistic personality trying to get love is conditional-positive objects, developing a false Self. The latter becomes a "Narcissus" is so cherished notions about himself, that his whole personality they identify exclusively with him. False Self passes from artificial cognitive and emotional structure becomes trapped and adapting the prosthesis to the individual "narcissus".

Clarify the author's view on the structure of the personality, organized by the narcissistic type, using the concept, which introduced Anze D. ${ }^{11}$ By analogy with the skin, as the boundary of the body, Anze identified metapsychological concept of "Skin I" ("I-skin") as a psychic envelope konteyniruyuschuyu structure of the mind, all the identification of the person, the whole personal experience, emotions and so on. As a TV personality, skin reflects influence of the external world, is the product of the continuous process of interaction. Leather - border barrier between the individual and the environment. Membrane-like skin structure allows interpenetrate and influence one another. As Anze wrote: "The skin is a barrier that protects and isolates himself from external objects, their possible intervention. The skin has a surface that captures relationships with others, it also means the best relationship support ". ${ }^{11}$ In their work Anze investigating two types of skin disorders formation $\mathrm{H}$. On the one hand, it is the formation of "holes" in it, the constitution of so-called partial / leaky skin. On the other hand, violation of the primary function of the skin may lead to the formation of a "second skin", when the child forms an adhesive identification, i.e. in its internal space, literally, stick together with the image of significant objects. Both types of violations are due to the 
deficit of contact mother and child when the latter frustrates needs not being met. violation of the primary functions of the skin can lead to the formation of a "second skin" when the child forms an adhesive identification, that is, in its interior, literally, stick together with the image of important objects. Both types of violations are due to the deficit of contact mother and child when the latter frustrates needs not being met. violation of the primary functions of the skin can lead to the formation of a "second skin" when the child forms an adhesive identification, that is, in its interior, literally, stick together with the image of important objects. Both types of violations are due to the deficit of contact mother and child when the latter frustrates needs not being met.

Now I try to structure previously said in a conceptual model. Skin I, according to Anze, body and emotions konteyniruet. But what then konteyniruet cognition? The answer to this question may be the introduction of a new concept - I-skin of the second order. The latter formed the intellectual constructs recognized anesthetize emotions due to their rationalization and explanation. The concepts of self-skin and the second order I-leather allow a deeper understanding of the phenomenon of narcissistic splitting of the ego to the true and the false Self. Cleavage is exfoliation of the skin-I of the second order from the I-skin. In his psychic world "daffodil" is concentrated in a layer of skin-I of the second order, it loads the libidinal energy of its own cognitive structures. And if I-leather - is a set of emotional identification, related, inter alia, with parental relations, then I-skin of the second order - a set of cognitive identities formed through processing of primary traumatic experience. She looks like a scar formed after injury, exfoliated from it, and, at the same time, maintain the integrity of their own cover. On the one hand, scars are less sensitive, on the other, they indicate the localization of psychic trauma.

Images of the self-object, idea of reference other are the "daffodil" in a layer of skin-I of the second order. This intellectual constructs that operate for the narcissistic personality is safe and presents no difficulty. "Kognitiziruya" Objects, "daffodil" is seeking control over them than reduce its own concern about the feelings about these objects. On the other experiences narcissistic person contact when experiencing real feelings, that is transferred to the level of I-skin. The skin I had irritated, inflamed, fragmentary, full of holes, which pushes the narcissistic subject from contact with her, and he returns to the level of a more integrated and flexible skin-I of the second order. Glossy and cognitive respectability last "daffodil" demonstrates with pride, showing it not only others but also themselves. More exciting discovery occurs when we look at the very I-skin. Underneath the "Narcissus" found no mental muscles, flesh, organs, bone, not feelings, experiences, psychological trauma, identity and ... emptiness. "Narcissus" will draw the libido of the "mental body", forwards it to the I-skin of the second order. He creates not only the body without organs, but the body without the body itself. Narcissistic personality is a leather bag wrapped in tissue of mental schemes I-skin second order.

This allows us to better understand the basic feelings of narcissistic personality. The experience of its grandeur due to the fixation of attention on the cognitive-designed I-skin contact of the second order, which includes, among other things, the ego-ideal. I-leather decorated with second-order Ideally, I like the fabric with precious stones, which allows the "Narcissus" feel brilliant and outstanding. Self-denial is due his skin Ya Being constituted of emotions generated by deficit ratios formed by the accumulation of negative identifications and rejections, she is irritated, allergenic and painful. Contact with it causes the subject's narcissistic feelings of helplessness and disgust. At the same time, even more interesting to explore shame "narcissus". The feeling of shame caused him not only that, instead of himself, he makes a false Self, impersonating of who really is not. A much greater degree of shame is explained by the lack of experience of himself as such. Narcissistic subject perceives itself as the invisible man, wrapped in a skin-packaging. He razotozhdestvlen with himself. To turn away the attention from himself, focus only on the cognitive identities of his personality attracts the "Narcissus" forgetting themselves, their emotions, their desires, and, subsequently, and develops fear to look inside, to get in touch with them. As a consequence, the narcissistic subject is formed mental neoplasm, in which he sees himself as a hollow, hollow. In my own experiences it - the void in the suit, decayed leper in satin brocade, where genuine disappeared forever lost. "Narcissus" feels terrific liar with self-experience, which can be put into words, "I feel that in me nothing!". It is connected with the experience of a special kind of libido oriented to split off a false Self in the form of I-skin of the second order.

Adapted once before due to parental love by moving away from themselves the real, having built a false project of the self, becoming narcissistic extension of the parents, "daffodil" leaves unfilled your true Self, which loses empathy link. His real self, in the absence of experience in self-experiences, deprived of parental love and narcissistic libido of the "Narcissus", shows itself only shortage, emptiness, dehiscence, failure. Most of the "Narcissus" is afraid that with him I pluck skin-second order and below do not find, in addition to the scraps I-rotted leather and painful feelings clusters. His main fear - not so much the fear of disappearing, as concerns about the exposure of the absence itself. I-leather second-order "Narcissus" - a kind of protective packaging, which contains it all fragmented mental guts, entrails and bones, libido is not fastened with glue. Narcissistic subject itself makes this package, doing endless reflection of themselves, their relationships, their own lives and so on. In a sense, the identity of the "Narcissus" is formed as a function of the surface as glossy reflection in the mirror I-skin of the second order. It is in a reflection of the "Narcissus" in love.

Now I focus on the features of the therapeutic strategy in dealing with personality, organized by the narcissistic type. Formulated therapeutic design allows several conclusions:

1. Narcissistic personality tend to establish the relationship with the therapist of a special kind, which I defined as a "cognitive transfer." This is due to two factors. Firstly, cognitive component has significant share in the structure experiences "narcissus". Second, narcissistic personality avoid "real" feelings, preferring to meditate than to experience them. "Kognitivizatsiya" relationship implies y narcissistic subject perception of the therapeutic interaction as "intellectual game into the beads." At the same time, this "game" can be very emotional for a therapist. "Narcissus" explores the therapist provokes him, keen to explore his identity in order to make a clear and safe for yourself. He seeks to intelligently assign a psychotherapist. If the latter will rely on their feelings, then it may be a "false feeling" of the situation. The therapist can begin to perceive the interaction as emotionally rich, involving both. For "daffodil" is not. It causes feelings in the therapist's purpose, he himself experiences in this exceptionally intelligent experience. He was "mentally tight." In this connection, for establishing therapeutic alliance therapist must be more than normally, oriented cognitive, intellectual respectable. On the one hand, he is tempted, "daffodil" in therapy, he enjoyed a special 
intellectual property. On the other hand, it builds interaction boundary. Note that all of this is the importance of the initial phase of therapy. The therapist can begin to perceive the interaction as emotionally rich, involving both. For "daffodil" is not. It causes feelings in the therapist's purpose, he himself experiences in this exceptionally intelligent experience. He was "mentally tight." In this connection, for establishing therapeutic alliance therapist must be more than normally, oriented cognitive, intellectual respectable. On the one hand, he is tempted, "daffodil" in therapy, he enjoyed a special intellectual property. On the other hand, it builds interaction boundary. Note that all of this is the importance of the initial phase of therapy. The therapist can begin to perceive the interaction as emotionally rich, involving both. For "daffodil" is not. It causes feelings in the therapist's purpose, he himself experiences in this exceptionally intelligent experience. He was "mentally tight." In this connection, for establishing therapeutic alliance therapist must be more than normally, oriented cognitive, intellectual respectable. On the one hand, he is tempted, "daffodil" in therapy, he enjoyed a special intellectual property. On the other hand, it builds interaction boundary. Note that all of this is the importance of the initial phase of therapy. He was "mentally tight." In this connection, for establishing therapeutic alliance therapist must be more than normally, oriented cognitive, intellectual respectable. On the one hand, he is tempted, "daffodil" in therapy, he enjoyed a special intellectual property. On the other hand, it builds interaction boundary. Note that all of this is the importance of the initial phase of therapy. He was "mentally tight." In this connection, for establishing therapeutic alliance therapist must be more than normally, oriented cognitive, intellectual respectable. On the one hand, he is tempted, "daffodil" in therapy, he enjoyed a special intellectual property. On the other hand, it builds interaction boundary. Note that all of this is the importance of the initial phase of therapy.

2. With the development of relations with the narcissistic subject, they are becoming more and more "personally unsafe 'to psychotherapist. Moreover, I would say that the relationship with the "Narcissus" - it's always a narcissistic injury for the therapist. It tends to put himself "daffodil." For him - it is a safe way to tell your therapist that he feels. He does this in many ways. For example, idealizes the therapist in the beginning and drastically devalue it at key stages of interaction when the therapist "emotionally open." Or he establishes control over the setting, ensure observance of the rules of the time, the frequency of meetings, the quality and timeliness of interpretations and so on. Or he's trying to break down the identity of the therapist on the conditional-negative and conditionally positive side, offering each of them has its own type of relationship. In this way, he arranges a kind of "emotional swings," undermines the prism of self-perception of the therapist, aims to control and domination. But an even greater challenge for the therapist is meeting with his own narcissistic part and "non-ideal" associated with it. By its very presence, "daffodil" satisfied with the meeting and challenges narcissistic radical psychotherapist. This meeting can not be avoided. Moreover, in many respects, the very therapy "narcissist" is accomplished at the expense of meeting the therapist with his narcissistic part. The "ideal" therapist is not able to help the narcissistic subject. It can set a new stage for the identification, will create additional stress, challenge perfectionism "narcissus", fall into the "I object," Ego forming new idealized standards but it can not resolve the internal dynamics of pathological narcissistic personality. He was "in a state of strain, but is not able to relax." It enhances the sense of narcissistic grandiosity than reinforces the second pole - a sense of insignificance. On the contrary, "vulnerable" therapist - a living man with his weakness and suffering, who is not afraid sealed in lats and cognitive armor personality "narcissus" and capable in her presence emotionally bare - just such a therapist creates the precondition for customer self-discovery with a narcissistic type of personality organization . I must say that emotionally naked in front of the "Narcissus" - not an easy task. Narcissistic subject so enhances the tone of the therapist's narcissistic, she finds new strength and power within his personality. The therapist is experiencing significant emotional burden, work with which it is necessary not only in the actual treatment, but also in space supervizionnyh groups. All this plays into the hands of the "Narcissus", for which "win" the therapist is not less important than to weaken their own symptoms. Narcissistic subject acts on the principle of "show me your weak spots and leave me the right to not show you mine," ie it wraps classical distribution of positions in psychotherapy. The "Narcissus" is inclined to launch attacks, to depreciate the person and work of the therapist. "Show me your weak spots and leave me the right to not show you mine," ie wraps classical distribution of positions in psychotherapy. The "Narcissus" is inclined to launch attacks, to depreciate the person and work of the therapist. "Show me your weak spots and leave me the right to not show you mine," ie wraps classical distribution of positions in psychotherapy. The "Narcissus" is inclined to launch attacks, to depreciate the person and work of the therapist. In the second phase of the "Narcissus" meets the ideal, the imperfection of the therapist, which forms at first a feeling of superiority, but also gives him the security space, a field in which he can relax. As in the first and in the second stage of psychotherapy narcissistic personality is mainly in the cognitive experiences, which I refer to as I-skin contact of the second order. For the therapist, these steps are the most difficult. However, after passing their therapist enters into the more familiar space of interaction with the client.

3. In the third stage, "daffodil" start "shuttle" contact with I-skin. Originally marked for him energized feelings of worthlessness, and imperfection. Narcissistic subject begins to need special support and emotional acceptance. He becomes vulnerable, open and receptive. Often, this is preceded by feelings of inner emptiness and associated feelings of shame. "Narcissus" is faced with a subjective inability to produce anything else but their absence and experiencing in connection with this existential fear. Adopting this state therapist has to subject narcissistic value correcting emotional experience (the term F.Aleksandera) and gradually leads to detection of the rejected fragment itself. The "Narcissus" is due to the extremely painful experiences. He was literally flooded with emotions that he, as it seems, is not able to withstand. "Narcissus" is located in the shuttle train, then touching the inflamed, painful part of himself, and finds refuge in the cognitive layer I-skin of the second order. He moves from hope to disappointment in himself / Therapy / therapist, from the I-experiences to a sense of his own nothingness and back. An important task for the therapist at this stage, in addition to taking function, becomes the formation of the "Narcissus" a special kind of curiosity himself. The basis for this is the development of curiosity, cognitive function narcissistic subject. The therapist also ensures its safe operation, care and support for their neutralizing its critical component. "Narcissus" is located in the shuttle train, then touching the inflamed, painful part of himself, and finds refuge in the cognitive layer I-skin of the second order. He moves from hope to disappointment in himself / Therapy / therapist, from the I-experiences to a sense of his own 
nothingness and back. An important task for the therapist at this stage, in addition to taking function, becomes the formation of the "Narcissus" a special kind of curiosity himself. The basis for this is the development of curiosity, cognitive function narcissistic subject. The therapist also ensures its safe operation, care and support for their neutralizing its critical component. "Narcissus" is located in the shuttle train, then touching the inflamed, painful part of himself, and finds refuge in the cognitive layer I-skin of the second order. He moves from hope to disappointment in himself /Therapy/therapist, from the I-experiences to a sense of his own nothingness and back. An important task for the therapist at this stage, in addition to taking function, becomes the formation of the "Narcissus" a special kind of curiosity himself. The basis for this is the development of curiosity, cognitive function narcissistic subject. The therapist also ensures its safe operation, care and support for their neutralizing its critical component. He moves from hope to disappointment in himself / Therapy / therapist, from the I-experiences to a sense of his own nothingness and back. An important task for the therapist at this stage, in addition to taking function, becomes the formation of the "Narcissus" a special kind of curiosity himself. The basis for this is the development of curiosity, cognitive function narcissistic subject. The therapist also ensures its safe operation, care and support for their neutralizing its critical component. He moves from hope to disappointment in himself/Therapy/therapist, from the I-experiences to a sense of his own nothingness and back. An important task for the therapist at this stage, in addition to taking function, becomes the formation of the "Narcissus" a special kind of curiosity himself. The basis for this is the development of curiosity, cognitive function narcissistic subject. The therapist also ensures its safe operation, care and support for their neutralizing its critical component.

4. The next stage of treatment of narcissistic personality is associated with the gradual redirection of libido from the idealized cognitive representations of himself as the ideal "insensibility» Self to the skin $\mathrm{H}$. This happens due to the transference relationship with the therapist, in which "the rose" faces and takes in the experience of the real interaction "sufficiently good" (not perfect) psychotherapist. This contributes to a gradual acceptance of emotional reality principle, which sets the true Self as a priority. The positive role played by intellectual pleasure from samoobnaruzheniya support therapist, corrective emotional experience, and others. Gradually libido glues fragments I-leather in a more holistic selfrepresentation, which will eventually become self-experiences. Positive mirroring in the eyes of the therapist gives additional integrity of narcissistic actors. From that moment, the development of the true Self, as a self-sufficient part of yourself. It attracts more and more mental glue in the form of libido, creating a certain stability of self-perception. The question that is open to me now: "Is it possible to form a narcissistic personality have a stable selfsupport function"? My experience can not be answered in the affirmative. "Narcissus" will continue to need in the reference that supports the person who returns the feeling to be "good enough" and takes the experience "nothingness." At the same time, these states have narcissistic personality is becoming less and sensitivity to others, empathy for their experiences increases.

\section{Acknowledgments}

None.

\section{Conflicts of interest}

The author declares that there is no conflicts of interest.

\section{References}

1. Freud Z. Essays on the psychology of Freud sexuality. Health. 1990:92-111.

2. Klein M. Development in psychoanalysis. Academic Project. 2001:512.

3. Balint M. The basic fault: Therapeutic aspects of regression. CogitoCenter. 2002:256.

4. Ocherki. Sketches dynamic psychiatry. Transcultural Study. Kabanova MM, Neznanova NG, editors. Saint-Petersburg: Institute. 2003:438.

5. Kernberg OF. Severe personality disorders. Strategy psychotherapy. Independent Firm “Class”. 2000:464.

6. Kohut X. Self regeneration. Cogito-Center. 2002: 316.

7. Kohut X. Analysis of the self X. Kohut: Systematic approach to the treatment of narcissistic personality disorders. Cogito-Center. 2003:368.

8. Winnicott DV. Young children and their mothers. DV Winnicott. 1998:80.

9. Lakan ZJ. Lacan instance of the letter in the unconscious or the fate of reason after Freud. Jacques Lacan. 1997:184.

10. Dorozhkin VR. Emotional discourses in psychotherapy. Counseling Psychology and Psychotherapy, 2015;2:181-195.

11. Anze D. I-skin. Trans. with fr. under the scientific. ERGO. 2011:302. 